\title{
Avoiding inappropriate urinary catheter use and catheter-associated urinary tract infection (CAUTI): a pre-post control intervention study
}

Vicki Parker ${ }^{1}$, Michelle Giles ${ }^{2 *}$, Laura Graham² ${ }^{2}$ Belinda Suthers ${ }^{3}$, Wendy Watts ${ }^{2}$, Tony O'Brien ${ }^{4}$ and Andrew Searles ${ }^{5}$

\begin{abstract}
Background: Urinary tract infection (UTI) as the most common healthcare-associated infection accounts for up to $36 \%$ of all healthcare-associated infections. Catheter-associated urinary tract infection (CAUTI) accounts for up to $80 \%$ of these. In many instances indwelling urinary catheter (IDC) insertions may be unjustified or inappropriate, creating potentially avoidable and significant patient distress, embarrassment, discomfort, pain and activity restrictions, together with substantial care burden, costs and hospitalisation. Multifaceted interventions combining best practice guidelines with staff engagement, education and monitoring have been shown to be more effective in bringing about practice change than those that focus on a single intervention. This study builds on a nurse-led initiative that identified that significant benefits could be achieved through a systematic approach to implementation of evidence-based practice.
\end{abstract}

Methods: The primary aim of the study is to reduce IDC usage rates by reducing inappropriate urinary catheterisation and duration of catheterisation. The study will employ a multiple pre-post control intervention design using a phased mixed method approach. A multifaceted intervention will be implemented and evaluated in four acute care hospitals in NSW, Australia. The study design is novel and strengthened by a phased approach across sites which allows for a built-in control mechanism and also reduces secular effects. Feedback of point prevalence data will be utilised to engage staff and improve compliance. Ward-based champions will help to steward the change and maintain focus.

Discussion: This study will improve patient safety through implementation and robust evaluation of clinical practice and practice change. It is anticipated that it will contribute to a significant improvement in patient experiences and health care outcomes. The provision of baseline data will provide a platform from which to ensure ongoing improvement and normalisation of best practice. This study will add to the evidence base through enhancing understanding of interventions to reduce CAUTI and provides a prototype for other studies focussed on reduction of hospital acquired harms. Study findings will inform undergraduate and continuing education for health professionals.

Trial registration: ACTRN12617000090314. Registered 17 January 2017. Retrospectively registered.

Keywords: Healthcare-associated infection, Catheter-associated urinary tract infection, Multifaceted intervention, Evidence-based practice

\footnotetext{
*Correspondence: Michelle.giles@hnehealth.nsw.gov.au

${ }^{2}$ Hunter New England Nursing and Midwifery Research Centre, James

Fletcher Campus, Gate Cottage, 72 Watt St, Newcastle, NSW, Australia2300

Full list of author information is available at the end of the article
} 


\section{Background}

Urinary tract infection (UTI) is considered the most common healthcare-associated infection (HAI) [1], accounting for up to $36 \%$ of all healthcare-associated infections (HAIs) [2]. Catheter-associated urinary tract infections (CAUTIs) represent the majority of UTIs (up to $67 \%$ of UTIs in all hospital inpatients [3], and up to $97 \%$ in ICUs [4]). Between 12 and $16 \%$ of hospitalised patients may receive a short term indwelling urinary catheter (IDC) [5], and many of these IDC insertions have been identified as unjustified or inappropriate [6]. CAUTI risk increases considerably with duration of catheterisation [7], and generates substantial care burden and significant hospitalisation costs, patient distress, embarrassment, discomfort, pain and activity restrictions [7-9]. A recent Australian study indicated that $1.7 \%$ of inpatients, hospitalised for $>48 \mathrm{~h}$, contract a UTI, adding additional days $($ mean $=4)$ to their length of stay (LoS) [10].

CAUTI is possibly the most preventable HAI [11], with significant potential cost savings. According to Mitchell et al.'s (2016) [10] calculations, there are 380,600 extra public hospital bed-days used each year in Australia due to healthcare-associated urinary tract infections (the majority being catheter-associated [3]). Umscheid et al. (2011) [11] estimate that each CAUTI costs between $\$ 1200$ and $\$ 4700$ USD. In the Australian setting, Jackson et al. (2011) estimated that the costs associated with a patient diagnosed with CAUTI are twice as much as a patient not affected by CAUTI [12].

\section{Preventing CAUTI}

Worldwide, there has been renewed interest and research into reducing the incidence of CAUTI, especially in the USA, with the introduction of non-payment for 'reasonably preventable' hospital-acquired complications [13]. An integrative review by Meddings et al. (2014) [1] evaluated interventions up to October 2012 to reduce IDC usage and CAUTIs. Meddings et al. (2014) found that interventions to reduce inappropriate IDC use, and bundles of interventions focusing on reducing unnecessary catheter use and general infection control were successful in reducing catheter use [1]. A component common to most urinary catheter bundles is timely catheter removal [14-20]. Meddings et al. recognised the importance of addressing socioadaptive factors in successfully implementing interventions [1]. These socioadaptive factors have since been addressed in the USA with the Agency for Healthcare Research and Quality (AHRQ) Comprehensive Unit-based Safety Program (CUSP). In a national US study, Saint et al. implemented CUSP in 926 units, and found a significant reduction in catheter use and CAUTI in non-ICUs [19]. Clinician education about recommended practice is a key part of interventions to address catheter use and CAUTI; nine studies since the Meddings et al. 2014 integrative review implemented a hospital (or multi-hospital) intervention to reduce CAUTI, and all included some form of education [14, 17, 19, 21-27]. Indeed, a systematic review of interventions to reduce device-related infections found that all interventions had some form of education as a key component [28].

From evaluating the literature on hospital-wide and multi-hospital interventions designed to reduce urinary catheter use and CAUTI, a gap was identified in study design; all identified studies used a pre-post design, which does not account for secular trends.

Studies investigating use of IDCs and CAUTI have been lacking in the Australian context [29, 30]. Extant literature includes hospital-based rates of IDC usage and/or rates of CAUTI, with some discussion of documentation, appropriate indications for IDC, and staff knowledge. Wynne et al. (2014) [29] found a point prevalence of $12.4 \%$ of patients with IDC in situ, in a tertiary teaching hospital in Melbourne. This included an acute inpatient facility and a sub-acute aged care and rehabilitation service. Wynne et al.'s study did not report on the days IDC in situ or prevalence of CAUTI, and a differentiation between short-term and long-term IDC usage was not made. So et al. (2014) conducted a chart audit in a hospital in Sydney, finding catheter utilisation of $11 \%$. A study of staff and patient knowledge of IDC usage in two general medical wards in a Melbourne hospital found that the mean time an IDC was in situ was 5.8 days, and that a physician's awareness of IDC presence was significantly associated with a shorter time IDC in situ [31]. Giles et al. (2015), in a pilot study, found the prevalence of IDCs in two wards in an Australian hospital (urology ward $=25 \%$; orthopaedic ward $=31 \%$, and rate of CAUTI $=2.2 \%$ [32]. Giles et al. then went on to describe the development and pilot of a bundled approach to target IDC utilization and CAUTI, however results of the intervention were not reported. A large point prevalence study in six Australian hospitals by Gardner et al. (2014) found a CAUTI prevalence of $0.9 \%$, and urinary catheter prevalence of $26.3 \%$ (88.7\% of these being IDCs) [33].

The foregoing studies highlight a gap in knowledge in the Australian healthcare context, in that there have been no studies investigating the effects of an intervention on reducing IDC utilisation and CAUTI rates in an acute care setting.

A multifaceted evidence-based intervention was piloted in two wards in an acute care hospital in the Hunter New England Local Health District, leading to a $50 \%$ reduction in IDC insertions, significantly reduced IDC duration and number of patients treated for CAUTI [34]. 
Building from the positive results from the aforementioned pilot, the present study aims to implement and evaluate an intervention across four acute care hospitals in NSW, Australia. To control for secular trends, implementation of the intervention will be phased across the hospitals.

\section{Methods/Design}

\section{Aims}

The primary aim of the study is to reduce IDC usage rates by reducing inappropriate urinary catheterisation and duration of catheterisation.

The secondary aims of the study are to identify:

1. The current inpatient indwelling urinary catheter usage rate and incidence of CAUTI;

2. If the implementation and adherence to bundled catheter care $(\mathrm{BCC})$ reduces IDC use and CAUTI;

3. How effective $B C C$ is in improving IDC-related outcomes;

4. The barriers and enablers to successful implementation of $\mathrm{BCC}$; and

5. The cost benefits of implementation.

\section{Design}

The study will employ a multiple pre-post control intervention design using a phased mixed method approach (Fig. 1).

Implementation of the intervention across four acute care hospitals will be staged, with multiple clusters in each of two implementation stages. Pre and post point prevalence data comparison will occur within all hospitals pre and post intervention, as well as between the two Health Districts as detailed in Fig. 1.

The staged implementation of the intervention allows for a control between the two Health Districts.
A mixed method design provides a platform to explore in-depth existing barriers and enablers related to implementing practice change. The sequential phased nature of the study ensures that the necessary evidence is available to inform the subsequent implementation phase of the study. The focus groups will identify barriers and enablers to implementation and uptake and will inform strategies to embed the intervention into normal practice. Questions in the focus groups will be informed by results from the point prevalence and clinician surveys.

The control will be usual urinary catheterisation practice, i.e., no intervention or implementation strategies. NSW Health evidence-based practice guidelines for "Adult Urethral Catheterisation for Acute Care Settings" [35], and local clinical practice guidelines for urinary catheterisation for each Health District are available for all clinicians, and can be accessed online.

The Clinical Excellence Commission (CEC), a corporation addressing patient safety and clinical quality in the NSW Health context, established a CAUTI project in 2014 to "help healthcare professionals in reducing the incidence of CAUTIs in acute care settings" [36]. A urinary catheterisation course on an online NSW Health learning platform also exists [37].

\section{Setting}

The intervention sites are four acute care hospitals from two Health Districts in NSW, Australia. Hospitals have been purposively selected, matched on total bed numbers, activity type and activity levels (See Table 1).

A key difference between the two health districts is the system used for medical health records: Health District 1 uses paper-based medical records, whereas Health District 2 uses electronic medical records. Data collection methods and training have been individualised to accommodate these differences.

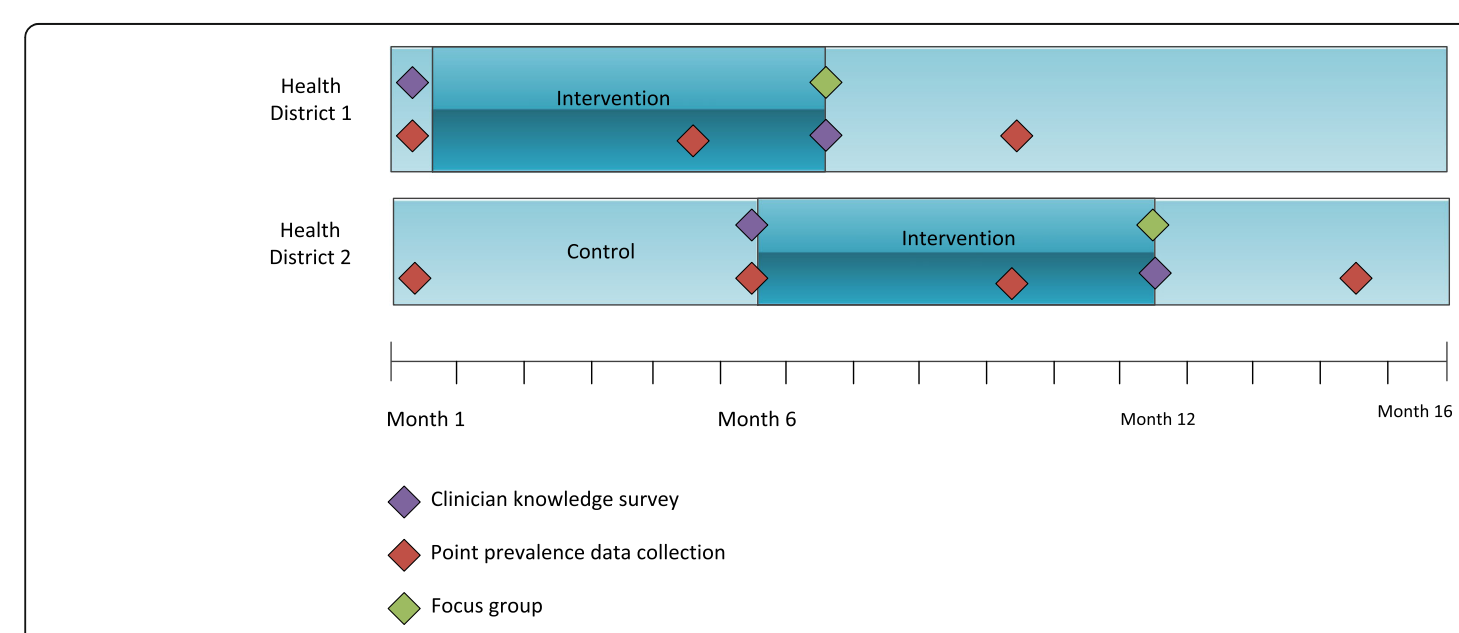

Fig. 1 Study Design. Data collection points are indicated with diamonds on timeline 
Table 1 Setting

\begin{tabular}{llc}
\hline Health District & Facility & Beds \\
\hline 1 & Hospital A & 360 \\
& Hospital B & 260 \\
& Total beds Health District $1=620$ \\
& Hospital C & 549 \\
& Hospital D & 318 \\
& Total beds Health District 2 $=867$
\end{tabular}

\section{Data collection}

Three main types of data will be collected:

- Pre and post implementation point prevalence and patient demographics (quantitative)

- Pre and post implementation clinician knowledge and competence (quantitative)

- Post implementation perceived barriers and enablers to implementation (qualitative)

Data collection types and details are outlined in Table 2, and the data collection timepoints are displayed in Fig. 1.

The point prevalence data will be collected by project staff (clinical nurse consultants, research assistant), nurse and midwife clinicians and clinical nurse educators from each hospital. Training will be administered to all clinicians involved on data collection techniques and definitions prior to collection, and they will be paired where possible with members of the research team. Data collection staff will go to every inpatient bed on every adult inpatient ward in the hospital and input data into a firewall protected online survey tool. Survey data will then be exported and merged with other electronically extracted demographic patient data into statistical package STATA [38] for analysis.

\section{Exclusion and inclusion criteria}

Point prevalence data will be collected from all adult inpatient wards across four hospitals in two Health Districts (excluding emergency departments, operating theatres and day only wards).

\section{Multifaceted intervention}

The intervention will be delivered in all adult inpatient wards, emergency departments, and operating theatres in all four hospitals. The key component of the intervention is the evidence-based "No CAUTI" bundle (Table 3). To support implementation of the No CAUTI bundle, the following resources were developed as part of the intervention:

- IDC insertion criteria guidelines

- Indications for IDC specimen collection

- Nurse-led IDC removal guidelines (Additional file 1)

- Educational resources and compliance auditing tools

The distribution and standardised use of a costeffective, generic IDC insertion pack forms part of the intervention. The insertion pack includes all equipment required for catheterisation, documentation stickers, and securing devices.

Table 2 Data collection sources and methods

\begin{tabular}{|c|c|c|c|c|}
\hline Data & Data collection method & Data source(s) & Data collected & $\begin{array}{l}\text { Data collection } \\
\text { timepoint(s) }\end{array}$ \\
\hline $\begin{array}{l}\text { IDC usage rate } \\
\text { and incidence of } \\
\text { CAUTI }\end{array}$ & Online data collection tool & $\begin{array}{l}\text { - Patient medical records - facility-wide } \\
\text { across all four hospitals } \\
\text { - Bedside observation } \\
\text { - Infection control database }\end{array}$ & $\begin{array}{l}\text { - Urinary catheter presence } \\
\text { - Days catheter in situ } \\
\text { - CAUTI rate }\end{array}$ & $\begin{array}{l}\text { - Baseline } \\
\text { - } 4 \text { months post- } \\
\text { implementation } \\
\text { commencement } \\
\text { - } 9 \text { months post- } \\
\text { implementation } \\
\text { commencement }\end{array}$ \\
\hline Patient profile & $\begin{array}{l}\text { Data extraction and then } \\
\text { merge with data from } \\
\text { point prevalence }\end{array}$ & $\begin{array}{l}\text { - Electronic patient management } \\
\text { systems }\end{array}$ & $\begin{array}{l}\text { - Patient demographics including } \\
\text { age, gender, weight, diagnosis, } \\
\text { type of admission }\end{array}$ & $\begin{array}{l}\text { - Baseline } \\
\text { - } 4 \text { months post- } \\
\text { implementation } \\
\text { commencement } \\
\text { - } 9 \text { months post- } \\
\text { implementation } \\
\text { commencement }\end{array}$ \\
\hline $\begin{array}{l}\text { Clinician } \\
\text { knowledge and } \\
\text { competency }\end{array}$ & Online survey & $\begin{array}{l}\text { - Clinicians (all nurses and medical } \\
\text { officers invited from participating } \\
\text { hospitals) }\end{array}$ & $\begin{array}{l}\text { - Clinician competency } \\
\text { - Clinician knowledge of CAUTI } \\
\text { prevention } \\
\text { - Perception of unit-based culture }\end{array}$ & $\begin{array}{l}\text { - Baseline } \\
\text { - } 6 \text { months post- } \\
\text { implementation } \\
\text { commencement }\end{array}$ \\
\hline $\begin{array}{l}\text { Barriers and } \\
\text { enablers to } \\
\text { implementation }\end{array}$ & Focus group & $\begin{array}{l}\text { - Clinicians (6-8 per facility) (all nurses } \\
\text { and medical officers invited from } \\
\text { participating hospitals) }\end{array}$ & $\begin{array}{l}\text { - Perceived barriers and enablers to } \\
\text { implementation }\end{array}$ & $\begin{array}{l}\text { - } 6 \text { months post- } \\
\text { implementation } \\
\text { commencement }\end{array}$ \\
\hline
\end{tabular}


Table 3 Evidence base for No CAUTI Bundle

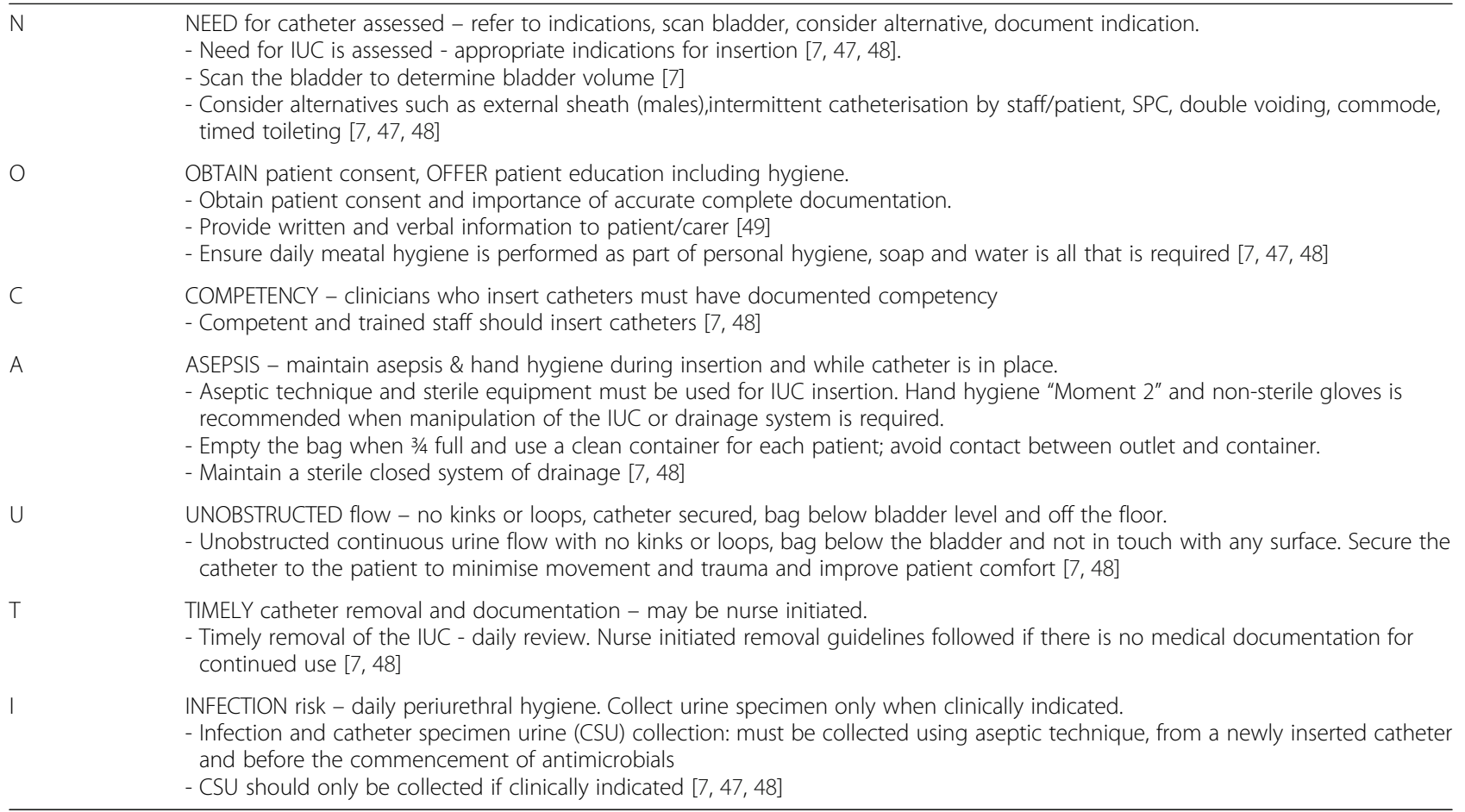

Routine assessment of clinician competency in urinary catheter insertion will be introduced as part of the multifaceted intervention.

\section{No CAUTI Bundle}

The "bundled intervention" framework used in this project is defined as a collection of a number of evidence based practices or steps, vital to achieving improvement in clinical outcomes [39]. The "No CAUTI" bundle was developed during the pilot project, and is based on evidence-based recommendations. The evidence for the bundled intervention is presented in Table 3.

\section{Implementation strategies}

A number of implementation strategies will be used in the project: education, monitoring and feedback, resources, and facilitation. The timing of implementation is displayed in Fig. 2. The Template for Intervention Description and Replication (TIDieR) was developed to improve the quality of descriptions of interventions [40], and can be used to report content of behavior change interventions, including what is delivered, who the intervention is delivered to, and what materials are used. TIDieR has previously been used to describe care bundle interventions [41]. The TIDieR framework has been used to outline the current implementation strategies in Table 4.
Whilst there are key implementation strategies that will be common to all intervention hospitals, there will be a degree of flexibility between the two Health Districts, and their hospitals. Both active (e.g. workshops, audit and feedback) and passive strategies (e.g. distribution and display of posters, equipment) will be used [28].

Previous studies have identified champions as playing a significant role in reinforcing practice change [42]. The need for multiple champions when implementing a large degree of practice change is recommended [43]; the current study will have a champion in each ward, and champions will meet regularly. Nursing staff are critical to the success of bundled interventions aimed at reducing IDC use [27].

\section{Power and sample size calculation}

A sample size calculation has indicated that 500 patients per Health District would be sufficient to detect a $40 \%$ fall (15 to $9 \%$ ) in relative IDC insertion rates with a power of 0.8 and alpha 0.05 . This is based on a $50 \%$ (39.5 to $14.6 \%$ ) reduction observed in the pilot study [34]. Estimated bed numbers of 860 in Health District 2 and 610 in Health District 1 should thus be more than adequate to provide sufficient power to detect a significant change. Further power will be obtained through having baseline control data and from stratifying the analysis by hospital wards. 


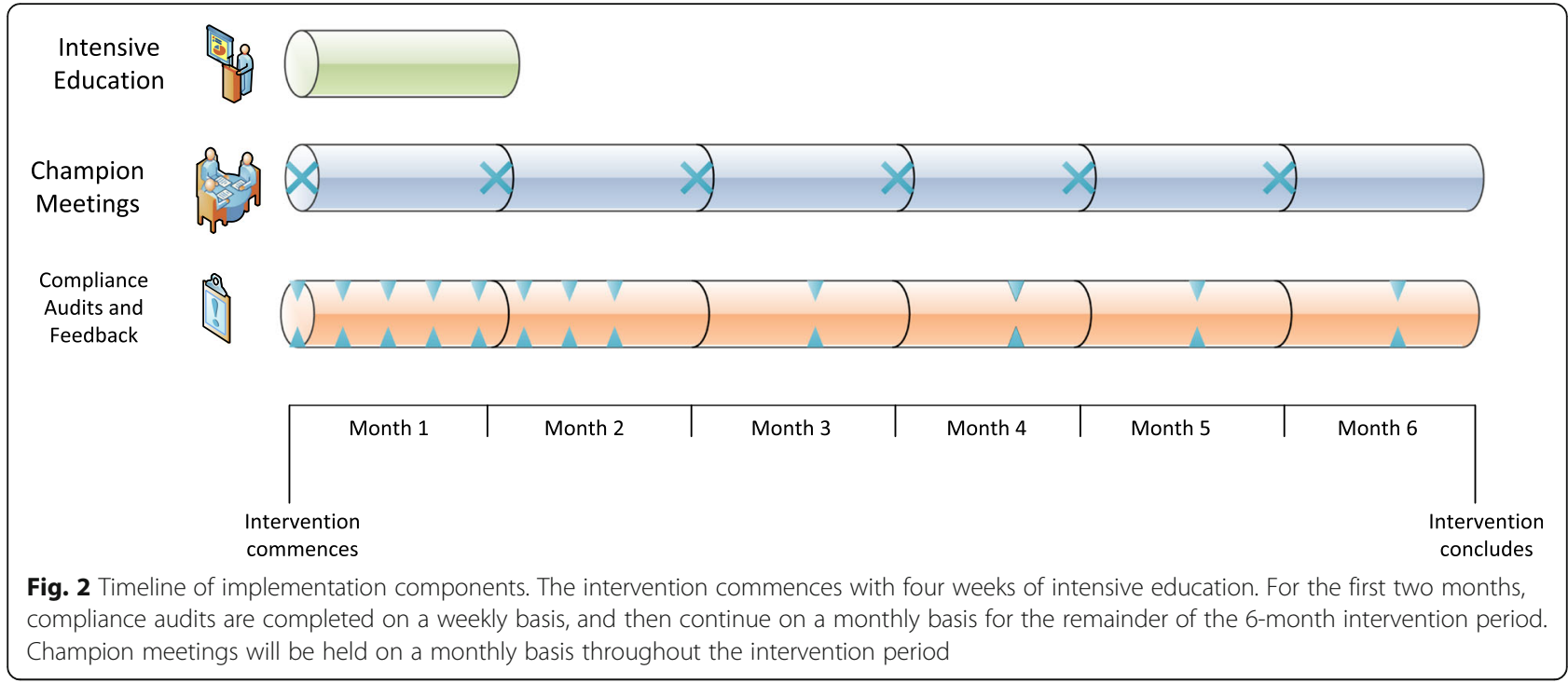

\section{Statistical analysis - point prevalence data}

Statistical analysis will be undertaken to determine differences in the prevalence of IDCs between Health District 1 (post) and Health District 2 (no intervention). A mixed methods analysis will compare pre and post data within the groups, across the time frame. Within group data will be stratified according to wards to allow for variation in the case mix of patients between wards. If differences in patient demographics are detected at baseline these will be controlled for in the between group analyses. Data linkage will be used to determine LoS and CAUTI rates for patients at each time point.

\section{Qualitative analysis}

All focus group interviews will be digitally audio-recorded and later transcribed verbatim by a professional transcriber/research assistant. Data will be analysed, coded and themed to low-level themes [44]. Cross-checking of coding will occur within the research team, and emerging themes will be shared within the whole research team as a check on credibility.

Using a mixed methods approach, the quantitative data from the point prevalence survey and the clinician survey will be analysed to inform the questions for the focus groups.

\section{Economic evaluation}

The economic evaluation will be based on a costeffectiveness analysis to determine whether the multifaceted care intervention is more cost-effective than usual care in reducing CAUTI amongst hospital inpatients. A healthcare provider perspective will be adopted. International guidelines for conducting economic evaluations, as recommended by Drummond et al.[45], and Husereau et al. [46] will be followed. Resource use will be identified using a short data collection instrument. Cost related data collected from usual care and intervention arms will include: materials used for catheterisation, proportion of patients receiving IDC, CAUTI rates, LoS for patients diagnosed with CAUTI, and CAUTI treatment expenses (e.g. antibiotics).

The measure of effect will be based on the change in the rate of CAUTI between the usual care and intervention groups. If the expected intervention benefit is demonstrated in the trial, the measure of effect will be the cases of CAUTI avoided due to the intervention. The economic analysis will identify the cost to avoid an additional case of CAUTI. The reportable outcomes will be average cost-effectiveness and incremental costeffectiveness ratios. A sensitivity analysis will be conducted to explore the robustness of the results to the uncertainty around parameters used in the model. The results will be interpreted in a broader decision making framework that includes acceptability and sustainability of the intervention. The economic sustainability of the intervention will be based on the cost and effect of delivering the intervention in a wider setting. The analysis will also report the resources required to implement the intervention in other localities. This information is relevant to policy makers because it reflects the resources required by other Health Districts to implement the intervention.

\section{Discussion}

A review of the literature highlighted a lack of interventional studies aiming to reduce IDC use or CAUTI rates in the Australian context. Internationally, there is a sparsity of studies using a control design in CAUTI intervention evaluations. 


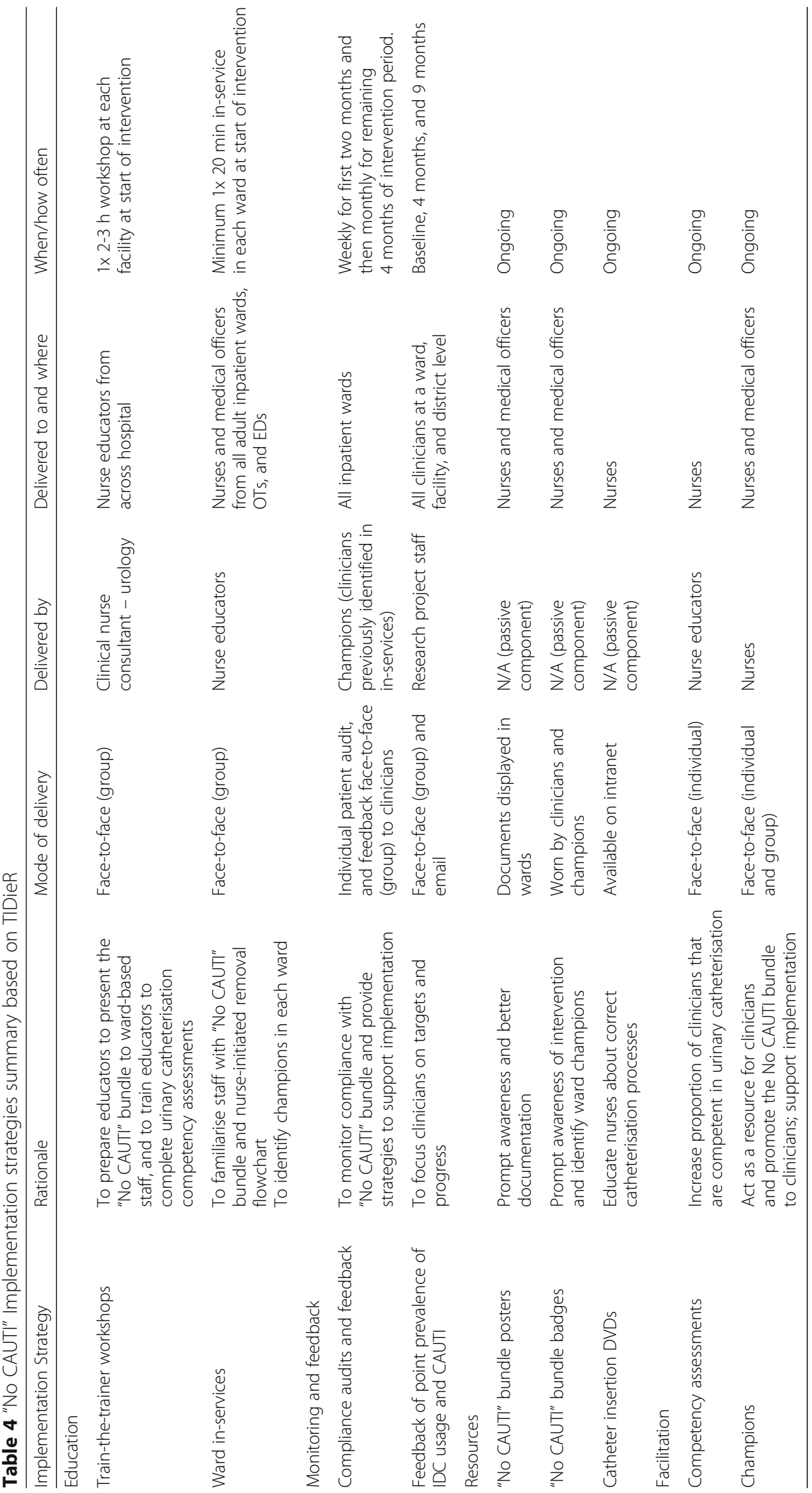


This study will add to the evidence-base through enhancing understanding of interventions to reduce CAUTI, using a control design to reduce secular effects.

Using the TIDieR framework, implementation strategies have been explicitly outlined, enabling easier replication of the intervention and implementation strategies. The use of a mixed methods approach will provide a platform to explore in-depth the existing barriers and enablers related to implementing practice change.

Ultimately, this study will improve patient safety through implementation and a robust evaluation of clinical practice and practice change.

\section{Additional file}

Additional file 1: Nurse-initiated IDC assessment and removal decision flowchart. (DOCX $152 \mathrm{~kb}$ )

\begin{abstract}
Abbreviations
AHRQ: Agency for Healthcare Research and Quality; CAUTI: Catheterassociated urinary tract infection; CEC: Clinical Excellence Commission; CUSP: Comprehensive Unit-based Safety Program; HAl: Healthcare-associated infection; IDC: Indwelling urinary catheter; LoS: Length of stay; TIDieR: Template for Intervention Description and Replication; UTI: Urinary tract infection
\end{abstract}

\section{Acknowledgements}

Not applicable.

\section{Funding}

Funding for the project has been granted through the NSW Ministry of Health Translational Research Grants.

\section{Availability of data and materials}

Not applicable.

\section{Authors' contributions}

VP and MG contributed to the development of research conception, design and methods and have significantly critically revised and contributed to the content in this manuscript. LG contributed to the initial drafting of this manuscript. BS contributed significantly to the development of the design and power and sample size calculation. WW contributed to the development of research conception, design and methods. TO contributed to the development of research conception, design and methods, and critically revised the content in this manuscript. AS contributed to the economic evaluation. All authors have read and approved the final manuscript.

\section{Competing interests}

The authors declare that they have no competing interests.

\section{Consent for publication}

Not applicable.

\section{Ethics approval and consent to participate}

Ethical approval has been granted through Hunter New England Local Health District's and Central Coast Local Health District's Human Research Ethics Committees (Ref 16/10/19/5.09 and 1016-097C respectively). Data will be stored on a secure network, protected by password and only accessible to members of the research team. A formal data monitoring committee was not warranted as there are known minimal risks. The collection and management of data is overseen by the research team. Patients will be receiving routine care in alignment with best practice principles in relation to IDC usage so consent is not required from patients. Healthcare professional participants will give informed consent to participate in focus groups and consent will be implied when they undertake the survey.

The conduct of the research is being overseen by a steering committee made up of experienced researchers and clinicians.

There will be a report to the NSW Health funding agency and the participating health districts, journal publications and conference presentations. Evaluation and outcomes will be disseminated to colleagues within and outside the participating health districts to inform sustainability of best practice related to urinary catheterisation and CAUTI prevention.

\section{Publisher's Note}

Springer Nature remains neutral with regard to jurisdictional claims in published maps and institutional affiliations.

\section{Author details}

${ }^{1}$ School of Nursing, University of New England, Armidale, NSW, Australia2351. ${ }^{2}$ Hunter New England Nursing and Midwifery Research Centre, James Fletcher Campus, Gate Cottage, 72 Watt St, Newcastle, NSW, Australia2300. ${ }^{3}$ Respiratory and General Medicine, John Hunter Hospital, Locked Bag 1 HRMC, New Lambton Heights, NSW, Australia2310. ${ }^{4}$ School of Nursing and Midwifery, University of Newcastle, Callaghan, NSW, Australia2308. ${ }^{5}$ Hunter Medical Research Institute (HMRI), New Lambton Heights, NSW, Australia2305.

Received: 2 February 2017 Accepted: 26 April 2017

Published online: 02 May 2017

\section{References}

1. Meddings J, Rogers M, Krein S, Fakih M, Olmsted R, Saint S. Reducing unnecessary urinary catheter use and other strategies to prevent catheterassociated urinary tract infection: An integrative review. BMJ Qual Saf. 2014; 23:277-89.

2. Allegranzi B, Bagheri Nejad S, Garcia Castillejos G, Kilpatrick C, Kelley E, Mathai E. Report on the burden of endemic health care-associated infection worldwide: A systematic review of the literature. World Health Organization. 2011. http://apps.who.int/iris/bitstream/10665/80135/1/9789241501507_eng. pdf. Accessed 25 Oct 2016.

3. Magill SS, Edwards JR, Bamberg W, Beldavs ZG, Dumyati G, Kainer MA, Lynfield R, Maloney M, McAllister-Hollod L, Nadle J, Ray S, Thompson D, Wilson L, Fridkin S. Multistate Point-Prevalence Survey of Health CareAssociated Infections. N Engl J Med. 2014;370(13):1198-208.

4. Richards MJ, Edwards JR, Culver DH, Gaynes RP. Nosocomial infections in combined medical-surgical intensive care units in the United States. Infect Control Hosp Epidemiol. 2000;21(8):510-5.

5. Association for Professionals in Infection Control and Epidemiology (APIC). Guide to preventing catheter-associated urinary tract infections. 2014. http://apic.org/Resource_/EliminationGuideForm/Off6ae59-0a3a-4640-97b5eee38b8bed5b/File/CAUTI_06.pdf. Accessed 25 Oct 2016.

6. Gokula RRM, Hickner JA, Smith MA. Inappropriate use of urinary catheters in elderly patients at a midwestern community teaching hospital. Am J Infect Control. 2004;32(4):196-9.

7. Gould CV, Umscheid CA, Agarwal RK, Kuntz G, Pegues DA. Healthcare Infection Control Practices Advisory Committee: Guideline for prevention of catheter-associated urinary tract infections 2009. Infect Control Hosp Epidemiol. 2010;31(4):319-26.

8. Yiou R, Audureau E, Loche CM, Dussaud M, Lingombet O, Binhas M. Comprehensive evaluation of embarrassment and pain associated with invasive urodynamics. Neurourol Urodyn. 2015;34(2):156-60.

9. Saint S, Olmsted RN, Fakih MG, Kowalski CP, Watson SR, Sales AE, Krein SL. Translating health care-associated urinary tract infection prevention research into practice via the bladder bundle. Jt Comm J Qual Patient Saf. 2009;35(9):449.

10. Mitchell BG, Ferguson JK, Anderson M, Sear J, Barnett A. Length of stay and mortality associated with healthcare-associated urinary tract infections: a multi-state model. J Hosp Infect. 2016;93(1):92-9.

11. Umscheid C, Mitchell M, Doshi J, Agarwal R, Williams K, Brennan P. Estimating the Proportion of Healthcare-Associated Infections That Are Reasonably Preventable and the Related Mortality and Costs. Infect Control Hosp Epidemiol. 2011;32(2):101-14. 
12. Jackson T, Nghiem HS, Rowell D, Jorm C, Wakefield J. Marginal costs of hospital-acquired conditions: information for priority-setting for patient safety programmes and research. J Health Serv Res Policy. 2011;16(3):141-6.

13. Meddings JA, Reichert H, Rogers MAM, Saint S, Stephansky J, McMahon LF. Impact of Non-Payment for Hospital-Acquired Catheter-Associated Urinary Tract Infection: A Statewide Analysis. Ann Intern Med. 2012;157(5):305-12.

14. Sampathkumar P, Barth JW, Johnson M, Marosek N, Johnson M, Worden W, Lembke J, Twing H, Buechler T, Dhanorker S, Keigley D, Thompson R. Mayo Clinic Reduces Catheter-Associated Urinary Tract Infections Through a Bundled 6-C Approach. Jt Comm J Qual Patient Saf. 2016:42(6):254-61.

15. Andreessen L, Wilde $M H$, Herendeen P. Preventing catheter-associated urinary tract infections in acute care: the bundle approach. J Nurs Care Qual. 2012;27(3):209-17.

16. Carter NM, Reitneier L, Goodloe LR. An Evidence-Based Approach To the Prevention of Catheter-Associated Urinary Tract Infections. Urol Nurs. 2014;34(5):238-45.

17. Clarke K, Tong D, Pan Y, Easley KA, Norrick B, Ko C, Wang A, Razavi B, Stein J. Reduction in catheter-associated urinary tract infections by bundling interventions. Int J Qual Health Care. 2013;25(1):43-9.

18. Harris TA. Changing practice to reduce the use of urinary catheters. Nursing. 2010;40(2):18-20.

19. Saint S, Greene MT, Krein SL, Rogers MA, Ratz D, Fowler KE, Edson BS, Watson SR, Meyer-Lucas B, Masuga M, et al. A Program to Prevent CatheterAssociated Urinary Tract Infection in Acute Care. N Engl J Med. 2016;374(22): 2111-9.

20. Titsworth WL, Hester J, Correia T, Reed R, Williams M, Guin P, Layon AJ, Archibald LK, Mocco J. Reduction of catheter-associated urinary tract infections among patients in a neurological intensive care unit: a single institution's success. J Neurosurg. 2012;116(4):911-20.

21. Egger M, Balmer F, Friedli-Wuthrich H, Muhlemann K. Reduction of urinary catheter use and prescription of antibiotics for asymptomatic bacteriuria in hospitalised patients in internal medicine: before-and-after intervention study. Swiss Med Wkly. 2013;143:w13796.

22. Fakih MG, Watson SR, Greene MT, Kennedy EH, Olmsted RN, Krein SL, Saint S. Reducing inappropriate urinary catheter use: a statewide effort. Arch Intern Med. 2012;172(3):255-60.

23. Fakih MG, Rey JE, Pena ME, Szpunar S, Saravolatz LD. Sustained reductions in urinary catheter use over 5 years: Bedside nurses view themselves responsible for evaluation of catheter necessity. Am J Infect Control. 2013;41(3):236-9.

24. Gray M, Skinner C, Kaler W. External Collection Devices as an Alternative to the Indwelling Urinary Catheter: Evidence-Based Review and Expert Clinical Panel Deliberations. J Wound Ostomy Continence Nurs. 2016:43(3):301-7.

25. Gray D, Nussle R, Cruz A, Kane G, Toomey M, Bay C, Ostovar GA. Effects of a catheter-associated urinary tract infection prevention campaign on infection rate, catheter utilization, and health care workers' perspective at a community safety net hospital. Am J Infect Control. 2016;44(1):115-6.

26. Miller B, Krein S, Fowler K, Belanger K, Zawol D, Lyons A, Bye C, Rickelmann M, Smith J, Chenoweth C, Saint S. A Multimodal Intervention to Reduce Urinary Catheter Use and Associated Infection at a Veterans Affairs Medical Center. Infect Control Hosp Epidemiol. 2013;34(6):631-3.

27. Parry MF, Grant B, Sestovic M. Successful reduction in catheter-associated urinary tract infections: focus on nurse-directed catheter removal. Am J Infect Control. 2013;41(12):1178-81.

28. Flodgren G, Conterno LO, Mayhew A, Omar O, Pereira CR, Shepperd S: Interventions to improve professional adherence to guidelines for prevention of device-related infections. Cochrane Database of Systematic Reviews. 2013(3). Art. No.: CD006559. doi: 10.1002/14651858.CD006559.pub2.

29. Wynne R, Patel M, Pascual N, Mendoza M, Ho P, Qian D, Thangavel D, Law L, Richards $M$, Hobbs L. A single centre point prevalence survey to determine prevalence of indwelling urinary catheter use and nurse-sensitive indicators for the prevention of infection. Healthcare Infection. 2014;19(1):13-9.

30. So K, Habashy D, Doyle B, Chan L. Indwelling urinary catheters: pattern of use in a public tertiary-level Australian hospital. Urol Nurs. 2014;34(2):69-73.

31. Harley G, Yeo AL, Stuart RL, Dendle C. A real-life snapshot of the use and abuse of urinary catheters on general medical wards. Infect Control Hosp Epidemiol. 2011;32(12):1216-8.

32. Giles M, Watts W, O'Brien A, Berenger S, Paul M, McNeil K, Bantawa K. Does our bundle stack up! Innovative nurse-led changes for preventing catheterassociated urinary tract infection (CAUTI). Healthcare Infection. 2015;20(2): 62-71.
33. Gardner A, Mitchell B, Beckingham W, Fasugba O. A point prevalence crosssectional study of healthcare-associated urinary tract infections in six Australian hospitals. BMJ Open. 2014;4(7).

34. Rohrmann S, Overvad K, Bueno-de-Mesquita HB, Jakobsen MU, Egeberg R, Tjønneland A, et al. Meat consumption and mortality - results from the European Prospective Investigation into Cancer and Nutrition. BMC Med. 2013;11:63.

35. NSW Health. Adult Urethral Catheterisation for Acute Care Settings. http:// www1.health.nsw.gov.au/PDS/pages/doc.aspx?dn=GL2015_016. Accessed 25 Oct 2016.

36. Clinical Excellence Commission (CEC). Catheteter-associated urinary tract infections (CAUTIs). http://www.cec.health.nsw.gov.au/patient-safetyprograms/adult-patient-safety/cauti-prevention. Accessed 25 Oct 2016.

37 Health Education \& Training Insitute (HETI). Inserting an Indwelling Urinary Catheter. http://www.heti.nsw.gov.au/Courses/Inserting-an-IndwellingUrinary-Catheter/. Accessed 25 Oct 2016.

38 StatCorp. Stata Statistical Software: Release 14. College Station: StataCorp LP; 2015

39 Institute for Healthcare Improvement. Bundle up for safety. http://www.ihi. org/resources/Pages/ImprovementStories/BundleUpforSafety.aspx. Accessed 25 Oct 2016.

40. Hoffmann TC, Glasziou PP, Boutron I, Milne R, Perera R, Moher D, Altman DG, Barbour V, Macdonald $H$, Johnston M et al. Better reporting of interventions: template for intervention description and replication (TIDieR) checklist and guide. BMJ. 2014;348.

41. Steinmo S, Fuller C, Stone SP, Michie S. Characterising an implementation intervention in terms of behaviour change techniques and theory: the 'Sepsis Six' clinical care bundle. Implement Sci. 2015;10(1):111.

42. Fakih M, Krein S, Edson B, Watson S, Battles J, Saint S. Engaging healthcare workers to prevent catheter-associated urinary tract infection and avert patient harm. Am J Infect Control. 2014;42:S223-9.

43. Damschroder LJ, Banaszak-Holl J, Kowalski CP, Forman J, Saint S, Krein SL. The role of the "champion" in infection prevention: results from a multisite qualitative study. Qual Saf Health Care. 2009;18(6):434-40.

44. Bazeley P. Qualitative Data Analysis: Practical Strategies. Australia: Research Support Pty Ltd; 2013.

45. Drummond MF, Sculpher GW, Torrance GW, O'Brien B, Stoddart GL Methods for the Economic Evaluation of Health Care Programs. Oxford: Oxford University Press; 2005.

46. Husereau D, Drummond MF, Petrou S, Carswell C, Moher D, Greenberg F, Augustovski A, Briggs J, Mauskopf J, Loder E. Consolidated Health Economic Evaluation Reporting Standards (CHEERS) - Explanation and Elaboration: A report of the ISPOR Health Economic Evaluation Publication Guidelines Good Reporting Practices Task Force. Value Health. 2013:16(2):231-50.

47. Tenke P, Koves B, Johansen T. An update on prevention and treatment of catheter-associated urinary tract infections. Curr Opin Infect Dis. 2014;27(1): 102-7.

48. Hooton TM, Bradley SF, Cardenas DD, Colgan R, Geerlings SE, Rice JC, Saint S, Schaeffer AJ, Tambayh PA, Tenke P, et al. Diagnosis, prevention, and treatment of catheter-associated urinary tract infection in adults: 2009 international clinical practice guidelines from the Infectious Diseases Society of America. Clin Infect Dis. 2010;50(5):625-63.

49. Oman KS, Makic MB, Fink R, Schraeder N, Hulett T, Keech T, Wald H. Nursedirected interventions to reduce catheter-associated urinary tract infections. Am J Infect Control. 2012:40(6):548-53.

\section{Submit your next manuscript to BioMed Central and we will help you at every step:}

- We accept pre-submission inquiries

- Our selector tool helps you to find the most relevant journal

- We provide round the clock customer support

- Convenient online submission

- Thorough peer review

- Inclusion in PubMed and all major indexing services

- Maximum visibility for your research

Submit your manuscript at www.biomedcentral.com/submit 